\title{
LITERATURA EM AULA DE LÍNGUA ESTRANGEIRA PARA CRIANÇAS: CAMINHOS PARA ABERTURAS DE HORIZONTES
}

\section{LITERATURE IN FOREIGN LANGUAGE FOR CHILDREN: WAYS FOR HORIZONS OPENINGS}

\author{
Mariana de Normando Lira ${ }^{1}$, Josilene Pinheiro Mariz ${ }^{2}$
}

\begin{abstract}
RESUMO: No âmbito do ensino de línguas para crianças, sabe-se da importância de um contato com linguas adicionais (SCHLATTER; GARCEZ, 2009) estrangeiras diversas desde cedo. Outrossim, estudiosos da área de literatura a apontam como um espaço especial para auxiliar no desempenho do aprendiz, contribuindo para o seu desenvolvimento de modo integral. Nestas reflexões, portanto, trazemos discussões que colocam a Intercompreensão de Linguas Românicas (ILR) como um caminho eficaz para favorecer uma aprendizagem plurilíngue e pluricultural, não dicotomizando língua e literatura no ensino de línguas para crianças (ALAS-MARTINS, 2014; PETIT, 2008; SANTORO, 2007). Assim, objetivamos trazer reflexões acerca da importância da presença do texto literário em aula de línguas adicionais para crianças pelo viés da ILR. Especificamente, intentamos discutir sobre os benefícios e os desafios ao se abordar o texto literário em aula de LE, utilizando-se tal metodologia.
\end{abstract}

PALAVRAS-CHAVE: Texto literário; LA para crianças; Intercompreensão de línguas românicas.

\section{ABSTRACT:}

In the field of language teaching for children, the importance of having contact with foreign languages at an early age is known. Also, scholars in the area of literature point to it as a special place to assist in the performance of the learner, contributing to his/her development in an integral way. In these reflections, therefore, we bring discussions that place the Intercomprehension of Romance Languages (ILR) as an effective way to promote plurilingual and pluricultural learning, not dichotomizing language and literature in the teaching of foreign languages to children (ALAS-MARTINS, 2008; PETIT, 2008; SANTORO, 2007). Thus, we aim to bring reflections about the importance of the presence of the literary text in a foreign language class for children through the ILR via. Specifically, we attempted to discuss the benefits and challenges of addressing the literary text in a FL class using such methodology

KEYWORDS: Literary text; FL for children; Intercomprehension of Romance languages.

\footnotetext{
${ }^{1}$ Mestranda do Programa de Pós-Graduação em Linguagem e Ensino da Universidade Federal de Campina Grande.

${ }^{2}$ Professora Associada na Unidade Acadêmica de Letras, da Universidade Federal de Campina Grande, atuando na graduação em Letras- Língua Portuguesa e Língua Francesa e na Pós-Graduação em Linguagem e Ensino.
} 


\section{Introdução}

Às portas do final da segunda década do século XXI, vive-se um momento delicado, no âmbito da educação no nosso país. Dentro desse contexto, por um lado, ainda se percebe a necessidade de uma política de internacionalização da Educação, que vem sendo alimentada no último decênio, a exemplo de ações e Programas como o Idiomas sem Fronteiras (IsF), que tem impactado o ensino de línguas estrangeiras no país (ALMEIDA; ABREU-E-LIMA; MORAES FILHO, 2017) e que foi gerado por uma demanda urgente, -do Programa Ciências sem Fronteiras (CsF)-, para dar formação básica de línguas estrangeiras ${ }^{3}$ para estudantes universitários que careciam fazer a mobilidade em universidades de países diversos de língua inglesa, francesa, italiana, alemã, só par citar algumas. Ora, do outro lado dessa necessidade de internacionalização, assistimos ao final do CsF e à atual fragilidade do já estabelecido IsF, levando-nos a constatar que mesmo em pleno século XXI, as políticas linguísticas que dariam conta de reflexões como bilinguismo, plurilinguismo e interculturalidade ainda continuam delicadas e ancoradas em uma única língua, a inglesa.

Para além de partidarismos linguísticos, pensar em internacionalização da educação é pensá-la pela ótica das políticas que percebam as diversidades linguísticas enquanto espaço que pode permitir essa abertura para novos horizontes. Considerando esse aspecto, o que dizer do ensino de línguas na escola? Sabe-se que a Base Nacional Comum Curricular (BNCC, 2018) propõe para o Ensino Fundamental, 'Competências de língua inglesa' que buscam, por exemplo: "Identificar o lugar de si e o do outro em um mundo plurilíngue e multicultural, refletindo, criticamente, sobre como a aprendizagem da língua inglesa contribui para a inserção dos sujeitos no mundo globalizado, inclusive no que concerne ao mundo do trabalho.” (BNCC, 2018, p. 202, destaque nosso). Parece-nos, minimamente, um discurso contraditório, uma vez que noções como plurilinguismo, multiculturalismo e globalização estão muito além de uma só língua. Com essa citação do documento oficial da educação, respondemos à pergunta feita acima: o ensino de línguas na escola é, na maioria das vezes, monolíngue e focada em uma língua de ensino, o que limita culturalmente o aprendiz em formação.

\footnotetext{
${ }^{3}$ Embora utilizemos o termo "Línguas Adicionais" (SCHLATTER; GARCEZ, 2009), em alguns momentos, utilizaremos Línguas Estrangeiras de acordo com o documento referido, como é o caso do CsF e do IsF.
} 
A partir dessas ponderações, o nosso olhar centra-se na formação plurilíngue da criança, tendo-se em vista entendermos que quanto antes a criança tiver contato com línguas diferentes, mais chances se tem de se viver em uma sociedade mais tolerante em todos os sentidos. Não é sem razão que muito se discute sobre a importância do contato da criança com línguas adicionais desde cedo e, a partir desse prisma, especialistas desse domínio vêm mostrando os benefícios de tal aprendizagem para o desenvolvimento da criança, para além de questões linguísticas (MOORE, 2006; VANTHIER, 2009; ROCHA; TONELLI; SILVA, 2010; TONELLI; PÁDUA; OLIVEIRA, 2017).

Nesse mesmo sentido, estudiosos apontam a literatura como um caminho muito especial para proporcionar um melhor desempenho do aprendiz contribuindo para o seu desenvolvimento de maneira integral como orienta a Lei de Diretrizes e Bases da Educação Nacional (LDB) ao tratar da educação infantil, em seu artigo $29^{\circ}$ da seção II; no qual afirma que "a educação infantil, primeira etapa da educação básica, tem como finalidade o desenvolvimento integral da criança até seis anos de idade, em seus aspectos físico, psicológico, intelectual e social, complementando a ação da família e da comunidade" (BRASIL, 1996). Ademais, estudos no domínio da literatura têm confirmado o quanto a leitura de obras literárias pode contribuir para o desenvolvimento da criança, tanto na aprendizagem da língua materna, quanto na aprendizagem de línguas estrangeiras (ZILBERMAN, 2003; SILVA, 2013).

Nessa busca por um caminho que proporcione aos professores e estudantes um sistema de ensino e aprendizagem em LE mais completo e eficaz, identificamos a Intercompreensão de Línguas Românicas (IRL ou IC), como um viés eficaz para favorecer uma aprendizagem plurilíngue e pluricultural (ALAS-MARTINS, 2014). Tal perspectiva de ensino vem ganhado espaço nas discussões entre os especialistas por possibilitar, de fato, o que orienta a BNCC, ao propor que a aula deve ser um lugar para "Identificar o lugar de si e o do outro em um mundo 'plurilíngue' e 'multicultural'”, conforme sinalizamos acima. Diante dessa realidade, portanto, entendemos que a leitura literária quando aliada à metodologia da IC pode em muito favorecer e contribuir no ensino de LE para crianças.

Partindo dessa realidade, nestas reflexões, objetivamos ponderar acerca da importância da presença do texto literário em aula de língua estrangeira ${ }^{4}$ (LE) para crianças; e, nesse

\footnotetext{
${ }^{4}$ Nestas reflexões, utilizaremos o termo língua estrangeira e não língua adicional, pois levamos em consideração a perspectiva de Derrida (1996), quando pensa na língua do outro, estranho a nós mesmos, pensamento partilhado por Kristeva (1988).
} 
contexto, enfocamos a ILR. De modo particular, intentamos verificar, ancoradas em trabalhos já realizados na área, quais são os benefícios e os desafios em aula de LE, para crianças, ao utilizar a metodologia da IC. A fim de apresentar uma possibilidade de trabalho por essa via, acrescentamos ainda uma proposta de material didático com texto literário para ser trabalhado com crianças na faixa etária entre sete e dez anos.

Para alcançarmos nossos objetivos, realizamos uma pesquisa bibliográfica visitando estudos de pesquisadores no âmbito da IC, tais como Capucho (2010) e Alas-Martins (2014); além dessa perspectiva, apoiamo-nos em reflexões acerca da importância do texto literário em aula de língua (SANTORO, 2011); da abordagem da literatura logo no início da formação em línguas sob a ótica de Pinheiro-Mariz, Silva e Silva (2017); e, ainda, sobre a importância do contato com os livros e com a literatura desde cedo, baseando-nos nas reflexões de Petit (2008), Cadermatori (2009) e Lagache (2006). Ainda, realizamos um levantamento em materiais impressos e digitais que podem ser utilizados no contexto de aula de língua através da IC.

\section{Ensinar língua estrangeira e formar leitores}

Entre pesquisadores e profissionais das Letras é comum a discussão sobre a relação entre o ensino de língua e de literatura em sala de aula e como estas vêm sendo abordadas, dando-nos, por vezes, a impressão de que não podem dialogar entre si. Embora se saiba muito bem, faz-se necessário lembrar que "língua e literatura permanecem ainda, na maior parte dos casos, dois campos separados do saber e, tanto nas escolas, quanto nas universidades, uma efetiva integração até hoje não se realizou" (SANTORO, 2007, p.11). Não se sabe exatamente a razão dessa dicotomia, mas, é fato que uma questão didática está na base dessa separação, causando, historicamente, um forte distanciamento entre as duas áreas que se constituem em base para a formação e atuação do profisssional de Letras.

No que diz respeito ao ensino de língua estrangeira, muitas vezes essa separação é ainda mais nítida, uma vez que ainda carregamos, apesar dos avanços, uma visão antiga de que o importante nesse contexto é aprender a gramática e o léxico para mantermos uma boa comunicação na língua alvo. De acordo com Santoro (2007), sobretudo a partir do momento em que a abordagem comunicativa foi se afirmando, "o texto literário foi, cada vez mais, substituído por textos que se acreditava [que] pudessem refletir de forma mais fiel a língua 
falada e cotidiana, isto é, a língua da "verdadeira comunicação"” (SANTORO, 2007, p. 18, grifos da autora).

Muito embora essa dissociação esteja consolidada nos currículos escolares e universitários, as discussões entre os pesquisadores caminham no sentido da importância em relacionar essas duas áreas do saber, uma vez que sua associação tende a favorecer uma aprendizagem mais completa. Além disso, é notável que língua está presente no texto literário, isto é, a literatura é construída a partir da melhor seleção de um léxico, explorando-se todas as potencialidades da linguagem. Com esse olhar, poderíamos afirmar que essa dicotomia só reduz as muitas qualidades do texto literário enquanto elemento essencial, sobretudo, em cursos de formação de professores, enquanto atores de novas formas do fazer docente.

Uma abordagem que instigue a um trabalho em que língua e literatura caminhem juntas, se torna ainda mais importante quando pensamos na concorrência entre o livro e a tecnologia, por exemplo (televisão, celulares, redes sociais etc). Além disso, de acordo com Michèle Petit (2008), a relação com a leitura é em grande parte uma história de família; nesse sentido, ela afirma que várias pesquisas confirmaram a importância da familiaridade precoce com os livros. No entanto, não raras vezes, essa relação com a leitura através da família não acontece, como nos mostra Cademartori (2009):

Nem todos os jovenzinhos têm em casa livros para escolher, nem acesso a uma biblioteca que possa estimulá-los, nem recebem das mãos de um parente ou amigo um livro que será marcante na vida deles. $\mathrm{O}$ acaso não surge como aliado para todos. Para a maioria, o único lugar onde o encontro com o livro pode acontecer é a escola, e pela intermediação do professor. (CADEMARTORI, 2009, p. 90).

Como pudemos confirmar, muitas vezes, a única oportunidade que a criança tem de ter contato com o livro é na escola. Entretanto, muitas de nossas escolas não possuem bibliotecas e nas poucas que possuem não é raro encontrar as que ficam, na maior parte do tempo, fechadas; outras vezes, os livros nem saem das caixas nas quais chegam à escola. Além disso, em um número significativo de situações, os profissionais não encorajam os aprendizes à leitura e até os proíbem de tocar nos livros para que permaneçam em “bom estado". Se essa é uma realidade mesmo para a literatura em língua materna, não é difícil chegarmos à conclusão de que a realidade é ainda mais preocupante se pensarmos na leitura de textos literários em 
línguas estrangeiras, particularmente, se for levado em conta que parece não haver um protocolo, nas escolas, a fim de estimular a leitura em outras línguas.

Daí, então, a importância de professores mediadores que enxerguem a leitura literária para além de um suporte que colabore com uma função mecânica e instrumental da linguagem, mas, sim, incentivem seus alunos a ler por prazer, uma vez que se a criança não tiver esse contato com o texto literário, escrito na língua alvo, durante a aula de LE, muito provavelmente, ela não o terá em nenhum outro lugar. Assim, o contato com o texto literário desde a infância pode ser um gatilho para o despertar do prazer pela leitura e do reconhecimento de sua importância, ainda que de forma implícita.

Além disso, é importante lembrar que o ensino de LE deve caminhar, de acordo com os documentos que regem a nossa educação, muito além das competências linguísticas, a exemplo da LDB citada na introdução deste trabalho e dos Parâmetros Curriculares Nacionais:

Torna-se, pois, fundamental, conferir ao ensino escolar de Línguas Estrangeiras um caráter que, além de capacitar o aluno a compreender e a produzir enunciados corretos no novo idioma, propicie ao aprendiz a possibilidade de atingir um nível de competência linguística capaz de permitir-lhe acesso a informações de vários tipos, ao mesmo tempo em que contribuía para a sua formação geral enquanto cidadão. (BRASIL, 2000, p. 26).

Por essa razão, entendemos que a partir do texto literário, podemos trabalhar temas que colaborem na construção da formação geral do aprendiz de LE, pensando em sua formação cidadã, o que pode ser possível uma vez que "o texto literário (...) reflete a cultura de um povo e possibilita a abordagem de questões relacionadas aos temas como a ética e a cidadania" (LIRA, 2017, p. 60). Ainda nessa mesma esteira, de acordo com Lagache (2006), a leitura é essencial na formação do indivíduo e é o conhecimento adquirido através dela que permite o acesso à liberdade de pensar e, portanto, à humanidade.

Igualmente, através da leitura literária a criança pode entrar em contato com novos mundos, diferentes culturas e formas de pensar, além de incitar a certa predisposição imaginativa despertada, segundo se pode constatar:

[...] um dos caminhos mais propícios para que o professor consiga aproximar a criança da LE é pelas sendas literárias; pois, enquanto obra de arte, a literatura é capaz de promover viagens, instigando o imaginário, levando a criança à invenção, criando os mais diversos seres que habitam no mundo de sua fantasia" (PINHEIRO-MARIZ; SILVA; SILVA, 2017, p. 105). 
Por certo, o imaginário infantil é um dos principais aliados de uma proposta que trabalhe com a literatura e ensino de língua estrangeira, pois, nos livros de historinhas, a criança tem a possibilidade de viajar em busca de novos caminhos. Quando se trata de uma abordagem em que se alinha línguas e literatura, esse imaginário infantil poder muito mais provocado, pois os sons de diferentes línguas têm certo poder sobre quem está diante desse novo som e, consequentemente, nova cultura.

Diante da possibilidade de conhecer novas línguas desde a infância, pode-se inferir que em um futuro, pode-se ter uma sociedade que tenha como comportamento comum, o respeito ao outro, considerando-o como diferente e não inferior. Certamente, é na infância que as construções de representações e estereótipos são firmadas e, partindo-se de uma abordagem que permite à criança ver para além de si mesma, pela sensibilização a uma língua distinta da sua, pode-se contribuir para a formação de cidadãos mais tolerantes e corteses.

\section{A IC em aula de língua para criança: dos beneficios aos desafios}

A nossa discussão sobre a leitura literária como elemento que pode, em muito, contribuir com o ensino de LE, estende-se a uma perspectiva que percebe a importância da formação para além de aprendiz de línguas, mas, pensada em formar leitores e cidadãos. Nesta seção, refletiremos mais especificamente sobre o ensino de LE para crianças através da metodologia da IC, ressaltando a sua contribuição para um ensino plurilíngue e pluricultural e nos desafios que são apresentados para que ela seja posta em prática.

É comum observarmos, nas publicidades de cursos de idiomas, o discurso de que estudar uma LE, normalmente o inglês, é um diferencial para o currículo. De fato, saber outra língua pode abrir portas no mercado de trabalho, no entanto, enquanto profissionais e pesquisadores da área, sabemos que os benefícios de aprendê-la vai muito além de questões profissionais. Em uma visão que vislumbra o outro lado desse discurso de "potencialize seu currículo" e "torne-se bilíngue em $x$ anos", um estudo adverte sobre a necessidade e a importância da imprescindível formação plurilíngue: "o discurso a respeito do plurilinguismo precisa tomar mais consistência nos diversos âmbitos da sociedade" (PINHEIRO-MARIZ, 2011, p. 204).

É também pensando nessa perspectiva de um ensino plurilíngue e pluricultural, que identificamos a IC como um caminho que favorece uma formação mais completa ao aprendiz, 
levando-o a perceber tantas línguas e tantas culturas, quanto possíveis, existentes no mundo, para além da inglesa que já está presente na escola e que acabou tornando-se sinônimo de LE diante da sua importância no mundo atual. Seguindo o caminho da diversidade linguística para fins de internacionalização (também), entende-se que o ensino de outra língua ainda na infância conflui para uma formação integral, em especial, quando a vemos pelas lentes do plurilinguismo:

um caminho para aproximar a criança de outros horizontes, para um mundo diferente do qual ela vive, permitindo que esse ser humano em formação venha a ter, o mais cedo possível, um contato mais abrangente com o mundo que o cerca. Com essa atitude, podemos estimular uma convivência mais harmônica, sobretudo, quanto ao respeito pelo outro que vive ao nosso lado e com quem se compartilha a vida, levando o ser humano, cujo caráter ainda está em construção, às relações interculturais, percebendo o outro a partir de si mesmo (PINHEIRO-MARIZ, 2011, p. 204).

Levando-se em conta essa visão que vê na aprendizagem da língua, um espaço de convivências interculturais, buscando-se relações de proximidades, ratificamos o quanto a IC pode ser benéfica, tendo em vista que ela nos propõe trabalhar com as línguas originárias do Latim; logo, línguas aparentadas. Por essa ótica, ela proporciona ao aprendiz um amplo conhecimento de língua e, principalmente, de culturas se considerarmos o fato de que cada língua é falada em vários países e, por conseguinte, está ligada à cultura de cada um desses países.

Expandindo-se de fatores de formação cidadã, através da IC também é oportuno motivar os pequenos aprendizes de LE, uma vez que esta metodologia oferece várias possibilidades de línguas latinas (francês, espanhol, italiano, catalão, galego, romeno e as línguas locais como franco-provençal, sardo, romanche, aragonês), para que eles possam decidir a quais almejam se dedicar a aprender de modo mais sistematizado e aprofundado. Igualmente, conhecer outras línguas, pode motivá-los às descobertas, mostrando que, a partir do conhecimento que eles já possuem, são capazes de compreender as outras línguas, sem que isso seja visto como algo distante de sua realidade, despertando, dessa forma, suas habilidades linguísticas.

Não obstante um número significativo de benefícios supracitados, a IC, enquanto metodologia relativamente recente, também encontra desafios, especialmente se pensarmos na sua aplicação ao público infantil. O primeiro desafio que podemos citar é o fato de que, como nos mostra Lira (2017), ao fazer uma breve retrospectiva sobre o ensino de LE no Brasil, este, 
aos poucos, foi se tornando cada vez mais monolíngue e voltado apenas para o público jovem e adulto. Por esse ângulo, encontramos muitas vezes a crença de que o inglês é suficiente, dificultando a aplicação da IC nas escolas. Logo, reconhecendo a importância do inglês no cenário atual, o que de fato nos inquieta é que "a língua inglesa seja apresentada como se fosse a única, ou pelo menos, a única que é importante de aprender, não se considerando as outras línguas e até mesmo alguma língua que partisse da motivação real do aprendiz" (LIRA, 2017, p. 63).

Outro desafio, este apontado por Capucho (2010), diz respeito à insegurança dos professores que têm medo de trabalhar com uma língua que não seja a sua de formação. No entanto, é importante ressaltar que "em práticas de IC, os professores não serão 'detentores de todo o saber', mas apenas praticantes de um método de descoberta das línguas, que deverão partilhar com os seus alunos." (CAPUCHO, 2010, p. 106). Essa afirmativa da pesquisadora portuguesa constitui-se em um dos principais pontos positivos da IC, pois, coloca o professor em lugar de humano, isto porque, de um modo geral, para o aprendiz, o mestre é aquele que detém o saber. Por esse mesmo olhar, a IC ajuda o professor a colocar-se no lugar do aprendiz, conduzindo-o à reflexão que dá espaço para a necessidade de saber aprender.

Acrescentamos aos desafios, um comportamento percebido a partir de uma experiência em participação de um projeto de extensão no qual pudemos trabalhar a metodologia da IC em uma escola da rede municipal de ensino da cidade de Campina Grande/PB ${ }^{5}$, diz respeito à dificuldade que as crianças apresentavam em relação à leitura e à escrita na própria língua materna. Tal constatação, por vezes, refletia na baixa autoestima delas, chegando a exprimir pensamentos tais como "a gente não sabe nem português direito, imagina as outras línguas". Assertivas como esta são recorrentes em pesquisas que abordam o ensino da língua inglesa na escola básica. Ora, poderia se constituir em uma problemática significativa o fato de que as crianças não aprendem sequer uma língua, como aprenderiam outras? É importante destacar que a nossa proposta pelas vias da IC intenta tão somente sensibilizar as crianças a conhecerem outros mundos, avançando um pouco mais que o inglês e, considerando-se que as línguas românicas têm a mesma raiz de nossa língua materna, se revela como um espaço de trocas de conhecimentos, aproximando mais o aprendiz de uma sensação de capacidade para aprender línguas. Outro aspecto interessante de apresentar é que o fato de ter a mesma raiz, dá

\footnotetext{
${ }^{5}$ O projeto intitulava-se Ensino de Línguas Estrangeiras na Infância: a Intercompreensão de Línguas Românicas Como Caminho para a Diversidade Linguística e Cultural e ocorreu no ano de 2017, atendendo crianças do $4^{\circ}$ e do $5^{\circ}$ ano do Ensino Fundamental I.
} 
à criança um pouco mais de conforto também em relação à própria língua portuguesa. Aqui, cabe citar a pesquisa de Silva (2017), na qual discute dados de sua pesquisa em que reafirma que através da aplicação da IC em aulas de Língua Portuguesa foi possível notar avanços por parte dos alunos na aprendizagem da LM, tanto na escrita quanto no despertar do interesse destes por leituras para além das trabalhadas durante a pesquisa.

\section{Da teoria à prática: uma proposta didática pelos caminhos da IC}

Até o presente momento de nossas discussões, temos apresentado reflexões sobre a IC de maneira teórica, isto é, sem enfocar de modo mais prático no que consideramos ser uma abordagem que dê suporte para uma formação mais integral da criança, a fim de formar cidadãos mais corteses e que sejam parte de uma sociedade mais tolerante. A partir deste momento, levaremos em consideração o quanto é importante a relação teoria e prática na relação língua e literatura pela IC, ressaltando-se o quanto ela pode contribuir tanto na formação linguística, quanto na formação leitora e cidadã das crianças. Pensando esse aspecto e após constatarmos a ausência de materiais didáticos que auxiliem na aplicação da metodologia da IC, sobretudo, para crianças e através do texto literário, apresentamos aqui algumas atividades de um caderno de IC elaborado por nós ${ }^{6}$, para que possamos perceber o quanto é possível unir estas áreas com o intento de proporcionar uma aprendizagem mais completa e prazerosa aos nossos pequenos aprendizes.

No caderno elaborado para fins de ensino de LE para crianças, partindo-se de textos literários, apresentamos poemas e fábulas em italiano, espanhol e francês, próprios para crianças, buscando estar mais próximo desse público e alinhando-se ao trabalho do professor, para despertar o gosto das crianças pela leitura. O intento é leva-las a conhecer e tentar compreender essas outras três línguas e as culturas a elas ligadas, trabalhando de forma lúdica e ainda fazendo relações com diferentes áreas do conhecimento, como a geografia e a história. Em uma parte temos os textos seguidos de atividades e em outra estão os textos "extras" para que o aprendiz possa ler simplesmente para descobrir o prazer da leitura literária, sem necessariamente vê-la como uma obrigação escolar.

Neste momento, a título de ilustração, apresentamos uma das fábulas trabalhadas no caderno de IC, intitulada La gallina de los huevos de oro. Essa fábula escrita em espanhol é

\footnotetext{
${ }^{6}$ Catalogado na Biblioteca Central da Universidade Federal de Campina Grande como material didático.
} 
também muito conhecida entre as crianças, por sua versão em português A galinha dos ovos de ouro. Esse é um ponto de partida para favorecer a motivação da aprendizagem na criança, fazendo-a perceber que o texto não está distante de sua realidade, bem como a língua que apresenta bastantes semelhanças com o português. Nesse caso, o professor já pode iniciar a aula com uma breve discussão a respeito do que as crianças conhecem dessa história, se gostam, onde a leram ou a ouviram etc. Em seguida, pode-se convidar as crianças para assistir ao vídeo que conta a história. Muitos vídeos estão disponíveis na internet contanto esta história em língua espanhola, mas, dentre os que encontramos, o que mais se aproximou da versão escrita foi o Cuenta Cuentos: La gallina de los huevos de oro. ${ }^{7}$ :

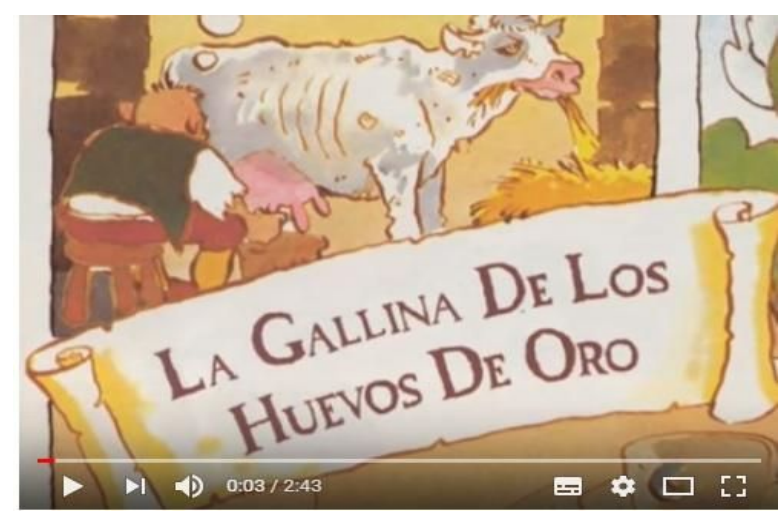

Fonte: Youtube.com

Assim, podemos trabalhar a (inter)compreensão oral junto às crianças, considerando ainda que há palavras na LA do texto que se aproximam mais na fala do que na escrita da LM. Vejamos, agora, como esta é apresentada na versão escrita do caderno de IC supracitado:

La gallina de los huevos de oro (Félix María Samaniego)

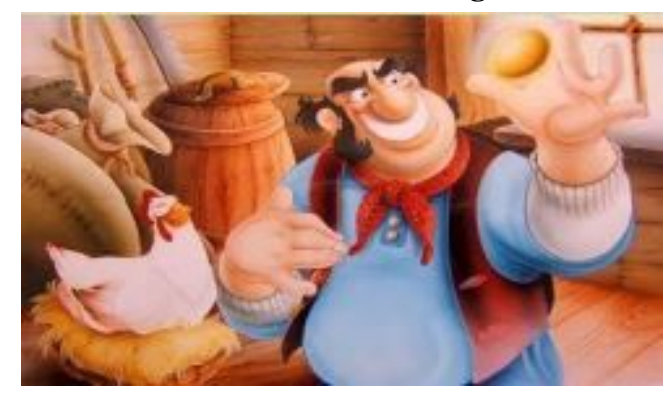

Érase una gallina que ponía un huevo de oro al dueño cada día. Aún con tanta ganancia, mal contento, quiso el rico avariento descubrir de una vez la mina de oro, y hallar en menos tiempo más tesoro.

\footnotetext{
${ }^{7}$ Disponível no YouTube através do link: https://www.youtube.com/watch?v=_btQjswDVjQ
} 
Matola; abriola el vientre de contado; pero después de haberla registrado ¿qué sucedió?

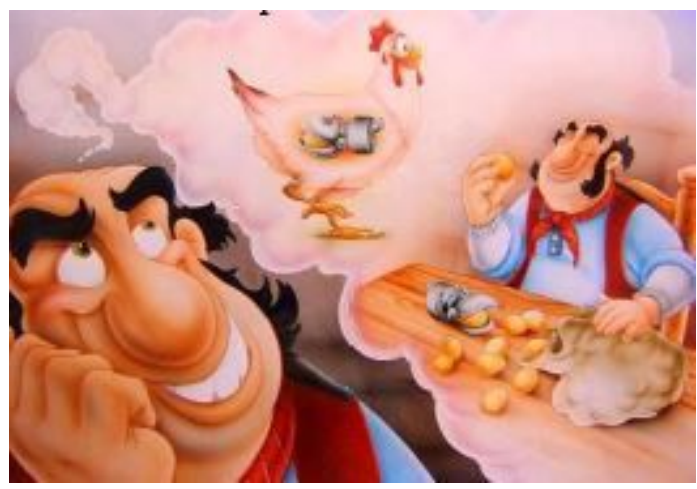

Que, muerta la gallina, perdió su huevo de oro, y no halló mina.

iCuántos hay que teniendo lo bastante, enriquecerse quieren al instante, abrazando proyectos a veces de tan rápidos efectos, que sólo en pocos meses, cuando se contemplaban ya marqueses, contando sus millones, se vieron en la calle sin calzones!

A partir da leitura do texto escrito, dá-se início ao momento em que professor e a criança iniciam as descobertas, desenvolvendo estratégias para compreensão do mesmo; algumas outras também podem ser realizadas durante a escuta e visualização da história em vídeo. Por exemplo, utilizar o auxílio das imagens, identificar as palavras que são iguais ou parecidas às de língua portuguesa, identificar o significado de outras através do contexto e, depois disso, fazer uma releitura mais atenta do texto.

As atividades elaboradas para o caderno de IC e que acompanham esse texto são também no intuito de colaborar com essa compreensão, conforme podemos ver abaixo:

1) Você consegue identificar em qual idioma o texto está escrito? Se a resposta for afirmativa, como você chegou a esta conclusão?

2) Qual o título e o autor da fábula? Você consegue compreender seu significado? Observe a imagem, ela pode te ajudar caso você tenha alguma dificuldade!

3) Sublinhe no texto as palavras que você compreendeu porque são parecidas ou iguais ao português. Compartilhe com seus colegas e veja se eles compreenderam as mesmas palavras que você.

4) Releia o texto com mais atenção. Qual (is) palavra (s) não parece (m) com o português, mas você conseguiu identificar graças ao contexto? 
6) Após conversar com o professor e os colegas sobre o que vocês conseguiram compreender na fábula acima, responda:

a) O que você pensa da atitude "del rico avariento"? Qual conselho você daria a ele em relação ao que fazer com "la gallina"?

b) Qual a lição/ensinamento passado pela fábula?

(LIRA; PINHEIRO-MARIZ, 2017)

$\mathrm{Na}$ atividade acima, observamos que há tanto questões voltadas para a (inter)compreensão do código linguístico, como questões para que as crianças reflitam acerca dos acontecimentos dos textos e se posicionem diante dele. É importante destacar a importância de, antes de qualquer outro objetivo, se trabalhar puramente o texto, dedicando um tempo para discuti-lo com os alunos, para que, assim, o texto não seja utilizado como pretexto para se trabalhar questões puramente linguísticas.

A atividade revela a flagrante aproximação entre a língua portuguesa e a espanhola, podendo ser, em um primeiro momento, um atrativo para a criança, pois ela é tomada por uma confortável sensação de capacidade de ler em outra língua, o que pode estimular a leitura e a compreensão da língua materna, auxiliando no desenvolvimento integral da criança (SHAFFER, 2009). É certo que a língua espanhola não se apresenta como uma língua de difícil aprendizagem para o aprendiz brasileiro; porém, é importante, desde uma primeira abordagem da língua, conscientizar a criança de que todos as línguas têm níveis de dificuldades diferentes. Todavia é muito importante recomendar que não vale a pena mostrar à criança apenas elementos que dificultem a aprendizagem, tais como os falsos cognatos ou um vocabulário muito distante de sua realidade, pois a intenção é fazer a criança conhecer os vários outros que existem para além daquele de sua língua e pra isso, ela precisa ser seduzida.

Evidentemente, este é apenas um exemplo do que a IC pode permitir quando ligada à leitura literária, buscando-se não dissociar a base de trabalho do profissional de Letras, língua da literatura, e em busca de atitudes plurilinguísticas desde a primeira formação escolar. Pois, para pesquisadores da IC, pode-se ter comportamento plurilíngue, mesmo sem sabermos (dominarmos) mais de uma língua estrangeira. Uma atitude plurilinguística é indispensável para ajudar o aprendiz a alargar as suas fronteiras linguísticas, haja vista que abrir para outras línguas pode ser apenas um pequeno começo para que ele vislumbre muitas outras realidades que vêm associadas à língua, como elementos sócio culturais que podem ser apresentados nas 
leituras literárias. Tal atitude pode ser um começo para abertura para o que está para além do conhecido e, nesses sentido, a língua estrangeira é fundamental.

Ancoradas nessa perspectiva que permite a abertura de horizontes linguísticos com foco no plurilinguismo, partilhamos da mesma visão de Nóbrega (2016, p.428), ao vislumbrar que "Integrando a linguística aplicada, a disciplina que aborda as políticas e os planejamentos linguísticos atrela-se completamente às necessidades do século 21 em relação a direitos linguísticos, globalização, multilinguismo e multiculturalismo". Ressalte-se que não é possível haver uma verdadeira internacionalização a partir do ponto de vista de uma língua. Por essa razão, faz-se necessário também que a nossa língua portuguesa circule nos espaços acadêmicos como possibilidade de diálogo entre línguas. Pensar em uma política linguística que leve a criança desde cedo a ter contato com outras línguas pode ser um caminho que a incite também à trocas interculturais. Para esse fim, nenhum outro caminho pode ser tão frutuoso quanto o da literatura, uma vez que a literatura, com suas características de polissemia, instigando o imaginário, encaminha a criança aos mundos distantes, promovendo descobertas.

A Linguística Aplicada não é recente no Brasil, datando de cerca de 50 anos, o que para uma ciência poderia ser vista como nova. É nessa juventude que identificamos a possibilidade de a LA abraçar, por exemplo, a Intercompreensão de Línguas Românicas, constituindo-se em caminho sine qua non para uma nova fase do ensino de língua em nosso país

\section{Considerações finais}

Pensar em um mundo plural, no qual se respeita o diferente, é um caminho bastante propício para se articular e construir uma sociedade sem preconceitos, inclusive linguísticos; nestas reflexões, discutimos o papel da Intercompreensão de Línguas Românicas como um caminho que pode permitir o alargamento de fronteiras desde a formação da criança, podendo se expandir para todas as idades. O fato é que as línguas adicionais têm um papel fundamental quando se trata de fazer pontes e estabelecer diálogos entre os diferentes. É por essa ótica que entendemos que internacionalizar é troca; é uma via de mão dupla, por ao mesmo tempo em que se aprende, se ensina também. Assim, ao aprender sobre uma língua diferente da sua, a criança depara-se com a sua própria língua, a língua portuguesa, que lhe permite dentre outras 
atitudes, quebras de paradigmas historicamente estabelecidos, o que pode, seguramente, tornar a criança mais tolerante. Então, o que seria a internacionalização nesse contexto de ensino de línguas para crianças? A resposta pode ser complexa, mas, é decididamente, o caminho que mais eficaz para a construção de um mundo sem pontes, considerando-se ser possível ajudar na educação seres humanos, conduzindo-os a serem mais tolerantes. $\mathrm{O}$ caminho é longo, mas, é na vase da educação humana que pode provocar as grandes transformações.

Ao longo destas reflexões, enfatizamos o quanto pode ser benéfico apresentar línguas às crianças desde cedo, pois, trata-se de um estratagema que pode nos ajudar a edificar uma sociedade sem barreiras de intransigências e, nesse espaço, as linguísticas ocupam um lugar basilar. Nesse sentido, entendemos que ensinar línguas às crianças é essencial na formação humana e, quando associada à literatura, torna-se indispensável, porque é uma forma de despertar o imaginário infantil, auxiliando a criança na edificação de uma formação integral, tendo o suporte da literatura com os seus elementos polissêmicos e de literariedade.

Pudemos perceber, através das reflexões aqui apresentadas, que a presença do texto literário em aula de língua estrangeira para crianças, através da IC, pode ser um gatilho para despertá-las também para o prazer da leitura literária, uma vez que muitas crianças só terão esse contato em ambiente escolar, com um caráter obrigatório, sem descobrir a ludicidade e o encanto que a literatura pode propiciar. Ademais, tal aspecto pode contribuir para sua formação integral enquanto cidadãos ativos, reflexivos, pensantes, críticos e compreensivos quanto às diferenças do outro.

Ainda colocamos em destaque o fato de haver desafios que precisam ser superados; no entanto, através da proposta apresentada e das leituras realizadas, conjecturamos que seja possível trabalhar o texto literário em aula de LE pelos caminho da IC. Além disso, consideramos importante destacar que a proposta apresentada aqui é apenas um caminho que pode ser seguido pelo professor, devendo este adequá-la ao seu público, a sua realidade, aos seus objetivos etc., pois não há uma fórmula pronta e acabada para que a IC seja posta em prática. Trata-se de um caminho, ainda com muitas descobertas a se fazer.

De fato, buscamos, nestas ponderações, discutir possíveis caminhos de como a IC pode ser colocada em prática pelos professores que acreditam na importância de uma educação plurilíngue e pluricultural, principalmente, quando se tem o texto literário como um eficaz aliado para isso, apontando as possibilidades que podem ser utilizadas para tanto, uma 
vez que, como vimos, muitos professores não se sentem seguros ao trabalhar com idiomas com os quais eles não tenham um conhecimento mais profundo.

Portanto, faz necessário reafirmar que pensar nas línguas adicionais como condição sine qua non para a internacionalização da educação em nosso país, neste século, é também pensar na formação humana e na expansão linguística; senão, estaremos apenas repetindo o que documentos como a BNCC (2018) que veem um pluri, multi, interculturalismo com uma só língua. É indispensável que, como formadores de novos professores, tenhamos também a consciência de que é preciso identificar instrumentos que deem o suporte necessário para que os nossos aprendizes sejam professores com uma visão mais aberta, capazes de ensinar línguas para crianças, por exemplo, arquitetando a constituição de uma sociedade com homens e mulheres mais conscientes de seu papel social.

\section{REFERÊNCIAS}

ALMEIDA, V. P.; ABREU-E-LIMA, D. M.; MORAES FILHO, W. M. Impacto do Programa Idiomas sem Fronteiras na formação de professores de línguas estrangeiras no Brasil. In: Revista Letras Raras. Campina Grande. EDUFCG. v. 6, n. 1. 2017.

BRASIL, Ministério da Educação. Parâmetros Curriculares Nacionais (Ensino Médio): parte II: Linguagem, códigos e suas tecnologias. Língua estrangeira moderna. Brasília: MEC, 2000.

BRASIL, Ministério da Educação. Base Nacional Comum Curricular. Brasília: MEC, 2018.

CADEMARTORI, L. O professor e a literatura: para pequenos, médios e grandes. São Paulo: Autêntica, 2009.

CAPUCHO, M. F. Ciência, ideologia, intervenção: a Intercompreensão para além das utopias. Synergies Europe n 5, 2010 p. 101-113.

DERRIDA, J. Le monolinguisme de l'autre. Paris: Editions Galilée. 1996.

KRISTEVA, J. Étrangers à nous-mêmes. Galimard: Paris. 1988.

LIRA, M. de N. A intercompreensão de línguas românicas no ensino de línguas estrangeiras para crianças através da leitura literária. 2017. 70 p. Trabalho de Conclusão de Curso (Graduação). Universidade Federal de Campina Grande, Campina Grande, 2017.

LIRA, M. de N. PINHEIRO-MARIZ, J. Caderno de Intercompreensão para Crianças. $36 \mathrm{f}$. Campina Grande: UFCG, 2018.

MOORE, D. Le Plurilinguisme à l'école. Coll. LAL. Didier: Paris, 2006.

NÓBREGA, M. H. da. Políticas linguísticas e internacionalização da língua portuguesa: desafios para a inovação. Revista de Estudos da Linguagem, Belo Horizonte, v. 24, n. 2, p. 417-445, 2016.

PETIT, M. Os Jovens e a leitura. Trad. Celina Olga de Souza. São Paulo: Editora 34, 2008. 
PINHEIRO-MARIZ, J. Da necessidade do ensino precoce da língua francesa em contexto exolíngue. In: CRUZ, N. C; PINHEIRO-MARIZ, J. Ensino de línguas estrangeiras: contribuições teóricas e de pesquisa. Campina Grande: Edufcg, 2011. p. 203 - 231.

PINHEIRO-MARIZ, J.; SILVA, B. S.; SILVA, J. L. F. Por uma formação plurilíngue e intercultural no desenvolvimento integral da criança. Revista Letras Raras. v. 6, p. 96 - 116, 2017.

ROCHA, C. H.; TONELLI, J. R. A; SILVA, K. A. (orgs.) Lingua estrangeira para crianças: Ensino-aprendizagem e formação docente. Campinas. Pontes Editores, 2010.

SANTORO, E. Da indissociabilidade entre o ensino de língua e de literatura: uma proposta para o ensino de italiano como língua estrangeira em cursos de Letras. 2007. Tese (Doutorado em Letras) - Departamento de Linguística, Universidade de São Paulo, São Paulo, 2007.

SILVA, J. A. da. Intercompreensão de línguas românicas e literatura na educação de jovens e adultos para a formação humana. 2017. 161 p. Trabalho de conclusão de curso (dissertação). Universidade Federal de Campina Grande, Campina Grande, 2017.

SILVA, M. R. S. Leitura literária em aula de FLE para crianças: entre o real e o simbólico. In: PINHEIRO-MARIZ, J. (org.). Em busca do prazer do texto literário em aula de línguas Jundiaí. Paco Editorial, 2013. p.122-p.135.

SHAFFER, D. Psicologia do desenvolvimento: infância e adolescência. Trad. Cintia Regina Pemberton Cancissu. São Paulo: Cengage Learning, 2009.

SCHLATTER, M.; GARCEZ, P. M. Línguas adicionais (Espanhol e Inglês). In: Rio Grande do Sul, Secretaria de Estado da Educação, Departamento Pedagógico. Referenciais curriculares do Estado do Rio Grande do Sul: linguagens, códigos e suas tecnologias. Porto Alegre: SE/DP, pp. 127-172. 2009.

TONELLI, J. R. A.; PÁDUA, L. de S.; OLIVEIRA, T. R. de. Ensino e Formação de Professores de Línguas Estrangeiras para Crianças no Brasil. Curitiba. Ed. Appris. 2017.

VANTHIER, H. L'enseignement aux enfants en classe de langue. Paris: CLE International, 2009.

ZILBERMAN, R. A literatura infantil na escola. São Paulo, Martins Fontes: Global, 2003.

Recebido em 30/04/2019. Aceito em 07/07/2019. 